\title{
Circadian activity rhythms of dwarf hamsters (Phodopus spp.) under laboratory and semi-natural conditions
}

\author{
Dietmar Weinert, Konrad Schöttner, Alexey V. Surov, Peter Fritzsche, \\ Natalya Yu. Feoktistova, Maria V. Ushakova \& Georgij B. Ryurikov
}

\begin{abstract}
The hamsters of the genus Phodopus ( $P$. campbelli, P. sungorus, P. roborovskii) inhabit different ecosystems facing them with different environmental challenges. This should have behavioural and physiological consequences, manifested genetically. Therefore, the present paper compares the daily activity rhythm of the three Phodopus species under various conditions, from highly standardized laboratory to semi-natural ones. Motor activity was recorded by the mean of passive infrared sensors (PIR), running wheels (RW) and ring-shaped sensors (RSS) placed on the burrow entrances.

Under standardized laboratory conditions with artificial light-dark cycles (L:D=14:10h or 18:06h), all hamsters were active almost exclusively during the dark time. The amount of general activity (PIR method) per day was not different between males and females or between species. The onset of activity (RSS) was significantly later in $P$. campbelli than in the two other species, the activity offset was earliest in $P$. roborovskii. The latter had also the shortest duration of dark-time activity. Running wheels were used mainly during the dark time (on average 97\%). P. sungorus did run significantly more than the other two species. On average they realized 9000 revolutions per day (ca. $3.5 \mathrm{~km}$ ).

The rhythm stability was lowest in P. sungorus. In some hamsters of this species, the activity onset was delayed by several hours, and the activity period was strongly compressed. Also, a free-running rhythm despite the presences of a light-dark cycle or arrhythmicity was observed in those animals. Differences between the species were also found during the last weeks of life. Whereas $P$. campbelli and P. roborovskii revealed clear activity rhythms until the last decade, in $P$. sungorus the activity rhythm disappeared from the last 100 days of life.

First studies under semi-natural conditions were performed at the Biological Station of the A.N. Severtsov Institute of Ecology and Evolution in Tchernogolovka. These included experiments in a laboratory though with natural lighting and temperature conditions and in outdoor enclosures. In one of them $\left(75 \mathrm{~m}^{2}\right)$ artificial nest boxes were provided, in the other two (400 $\mathrm{m}^{2}$ each) the animals could dig their own burrows. The observed activity patterns are similar to those obtained under constant, standardized conditions. Moreover, the animals did clearly respond to the changing photoperiod.

The activity patterns of each species described in the present paper are rather similar under semi-natural and artificial environmental conditions. This can be taken as evidence that the obtained species-specific patterns have a genetic basis and are not caused by the different environmental conditions.
\end{abstract}

KEY WORDS: Phodopus, motor activity, daily pattern, stability, aging.

Dietmar Weinert [weinert@zoologie.uni-halle.de], Konrad Schöttner, and Peter Fritzsche, Institute of Biology, Department of Zoology, Martin-Luther-University, Halle-Wittenberg, Domplatz 4, D-06108 Halle, Germany; Alexey V.Surov [surov@sevin.ru], Natalya Yu. Feoktistova, Maria V. Ushakova, and Georgij B. Ryurikov, A.N.Severtsov Institute of Ecology and Evolution Russian Academy of Sciences, Leninskii pr. 33, Moscow 119071, Russia.

\section{Циркадные ритмы хомячков рода Phodopus в лабораторных и полуестественных условиях}

\author{
Д. Вейнерт, К. Шотнер, А.В. Суров, П. Фрицше, Н.Ю. Феоктистова, \\ М.В. Ушакова, Г.Б. Рюриков
}

РЕЗЮМЕ. Хомяки рода Phodopus (P. campbelli, P. sungorus, P. roborovskii) населяют биотопы, отличающиеся по экологическим характеристикам. Это может приводить к различиям в экологии, поведении и физиологии, закрепленных генетически. В данной работе сравниваются суточные ритмы активности трех видов рода Phodopus в различных условиях, от высоко стандартизированной лаборатории до полуестественных. Двигательную активность регистрировали датчиками движения, колесами активности и специальными сенсорными кольцами, помещенными во входы в норы. В стандартизированных лабораторных условиях с искусственными фотопериодами (14 час. день и 10 час. - ночь и 18 час. день и 6 час. - ночь) все хомяки были активны в основном в течение 
темного времени. Суммарная активность (датчики движения) в течение суток не различалась у самцов и самок и между видами. Начало активности (сенсорные кольца) у P. campbelli nриходилось на более позднее время, чем у двух других видов, раньше других активность завершалась у $P$. roborovskii, у которого был самый короткий период активности в темное время. Колеса активности использовались зверьками, главным образом, в течение темного времени (97\%). P. sungorus действительно пробегал значительно большее расстояние, чем другие виды (в среднем 9000 оборотов в день, что соответствует расстоянию в 3,5 км). Стабильность ритма была самой низкой у P. sungorus. У некоторых зверьков этого вида начало активности было отсрочено на несколько часов, и период активности сокращен, у них же наблюдалась аритмичность активности. Межвидовые различия были обнаружены в течение последних недель жизни. Так, P. campbelli и P. roborovskii coхраняли четкие ритмы активности до последней недели жизни в отличие от P. sungorus, у которого ритмы исчезли уже за 100 дней до смерти.

Впервые исследования в вольерах при естественных световых и температурных условиях выполнены на Научно-экспериментальной базе «Черноголовка» Института проблем экологии и эволюции им. А.Н.Северцова РАН. В одной из вольер (75 кв.м) были установлены искусственные убежища, в двух других (по 400 кв.м) животные могли копать свои собственные норы. Животные четко реагировали на естественный фотопериод. Другие параметры активности в целом совпадают с полученными в постоянных стандартизированных условиях. Это может быть свидетельством, что видоспецифические особенности являются следствием накопленных генетических различий, а не адаптациями к различным условиям окружающей среды.

КЛЮЧЕВЫЕ СЛОВА: Phodopus, двигательная активность, суточная активность, стабильность ритмов, старение.

\section{Introduction}

The genus Phodopus consists of three species Phodopus sungorus (Pallas, 1773), Phodopus campbelli (Thomas, 1905) and Phodopus roborovskii (Satunin, 1903). They inhabit different ecosystems like Asian steppes, semi-deserts and deserts. The different environmental challenges particularly concerning temperature, food and water resources, should have consequences for animals' physiology and behaviour. However, comparatively little is known about these hamsters. This does concern mainly field but also laboratory data.

Whereas numerous (laboratory) studies were dedicated to the circadian activity rhythm of $P$. sungorus (Puchalski et al., 1996; Steinlechner et al., 2002; Ruby et al., 2004; Barakat et al., 2005; Weinert \& Schöttner, 2007), the activity patterns of the two other species have rarely been investigated. According to Flint (Flint, 1966), $P$. sungorus and $P$. campbelli are nocturnal and crepuscular. Hamann (Hamann, 1987) investigated the daily activity patterns of $P$. campbelli and $P$. roborovskii. Colonies of 8 individuals each were kept under long photoperiod and the exit from and the entry into the burrows were recorded. $P$. campbelli was found to be active outside the nest-burrow also during the light period, whereas the surface activity of $P$. roborovskii was more closely related to the dark time. WynneEdwards and colleagues (Wynne-Edwards et al., 1999) investigated $P$. sungorus and $P$. campbelli in their natural habitats. Both species were nocturnal, however $P$. campbelli arose earlier and remained longer above ground than P. sungorus. Similar differences the authors found under controlled laboratory conditions, though only females (n=6 or 7 ) were investigated. $P$. campbelli began wheel running earlier, remained running longer and had run farther by the end of the day.

Despite some similarities, the above mentioned results are not consistent. This might be caused by differences in the experimental conditions (natural vs. artificial lighting, environmental temperature etc.). Moreover, different methods to record activity were used (entry into and exit from the burrows, above ground activity, wheel running). Also in most cases, the sample size was low and not all three species were investigated simultaneously. For that reason the present study was performed.

We did investigate the daily activity rhythm of the three Phodopus species under different environmental conditions. Highly standardized laboratory studies were performed at the Institute of Biology/Zoology in Halle. Another set of experiments was carried out at the Biological Station of the A.N. Severtsov Institute in Tchernogolovka (Moscow region). This included laboratory studies under natural lighting conditions. Also, outdoor enclosures were used.

In the laboratory, motor activity was investigated by means of passive infrared (PIR) motion detectors. This enabled us to record the general activity of the animals and to avoid any feedback effects of the registration apparatus. In some experiments, running wheels where used to record locomotor activity as this is the method of choice in many chronobiological studies (Mrosovsky et al., 1998). Also, according to various authors, wheelrunning activity may be a good estimate for the foraging activity outside the burrow (Rusak, 1989; Wollnik et al., 1991). In the outdoor experiments, special rings were fixed to the entrance of the nest boxes or the 
burrows. These enabled us to monitor the entrances into and the exits from the burrow individually for each animal. The time spent outside was used as an estimate of surface activity.

The animals of both study sites were of similar geographic origin. At the institute in Halle, laboratory colonies of $P$. sungorus (originated from Khakassia, Russia), $P$. campbelli (originated from eastern Mongolia), $P$. roborovskii (originated from Zaisan, Kazakhstan) were established in 2000. The animals were kindly provided by N.Y. Vasileva (A.N. Severtsov Institute of Ecology and Evolution Russian Academy of Sciences, Moscow, Russia). In 2003, we got additional breeding pairs of $P$. sungorus from S. Steinlechner (School of Veterinary Medicine, Hannover, Germany) and K. Rudloff (Tierpark, Berlin, Germany) which had the same geographic origin (Novosibirsk region).

\section{Material and methods}

Investigations were carried out on males and females of different age (for details, see Results). In Halle, hamsters were kept in air-conditioned windowless rooms in standard plastic cages (Macrolon ${ }^{\circledR}$ Type II or III) with wire mesh tops. Animal bedding (All$\operatorname{span}^{\circledR}$, The Netherlands) was renewed every two weeks. Food pellets (one part breeding diet Altromin ${ }^{\circledR} 7014$, two parts maintenance diet Altromin ${ }^{\circledR} 7024$; Altromin $\mathrm{GmbH}$, Lage, Germany) and tap water were provided ad libitum. The light/dark condition was L:D $=14: 10 \mathrm{~h}$ with lights on from 04:00 - 18:00 h or L:D = 18:06 h with lights on from 02:00 - 20:00 h Central European Time and a light intensity of about 80-100 lx (light period) and $0 \mathrm{~lx}$ (dark period). The room temperature was $22^{\circ} \mathrm{C} \pm 2{ }^{\circ} \mathrm{C}$, the relative humidity varied between 60 and $65 \%$. In Tchernogolovka, the animals were also kept and bred in a laboratory though under natural lighting and temperature conditions. Vegetables, seeds (sunflower, oat) and water were available ad libitum. Once per week, soft cheese was provided. To investigate hamsters under environmental conditions more close to natural ones, animals were released to outdoor enclosures. A smaller one had an area of about $75 \mathrm{~m}^{2}$. The ground was covered with wire mesh, and artificial nest boxes were provided. In the other two enclosures (400 $\mathrm{m}^{2}$ each) the animals could dig burrows by themselves.

For laboratory studies, passive infrared (PIR) sensors were mounted above the cage roof in such a way that they detected motions of the hamsters in all sectors of the cage. The running wheels had a diameter of 12.5 $\mathrm{cm}$ and a $6 \mathrm{~cm}$ wide running area. They were equipped with magnet switches. The impulses from the PIR detectors and from the running wheels were stored and analyzed by means of the "Chronobiological Kit" (Stanford University, USA).

To record the surface activity in outdoor enclosures, a so called "Field Animal Identification System" (FAIS) was used. It consists of plastic rings equipped with an antenna and two infrared light barriers one above the other. These rings were placed at the entrance of the burrows or the nest boxes. Hamsters were marked individually with PIT tags (Passive Integrated Transponder) that were implanted under the skin. The order of interrupting the light barriers indicated whether a hamster did enter or leave a burrow/nest box. At the same time, the code of the PIT tag was registered by the antenna. An attached data logger did record and store the data. Every fourth day on average, the data were transferred to a notebook for further analyses.

Results of laboratory studies were depicted as double-plotted actograms or mean value chronograms, and these allowed a visual analysis of the data. To characterize the rhythms quantitatively, the total activity per day and the percentage of total activity per $24 \mathrm{~h}$ accounted for the dark phase were calculated. The times when the daily curve went above or below the 24-h mean value were taken as activity onsets and offsets. A $\mathrm{Chi}^{2}$-periodogram analysis was performed by means of the Chronobiology $\mathrm{Kit}^{\circledR}$ to estimate the period length of the circadian activity rhythm and its stability $\left(Q_{p}\right)$. Data were always presented as arithmetical means \pm SEM. ANOVA and tests on statistical difference were performed using the software package SPSS 12.0. The level of significance was set at $p<0.05$. Exact $p$-values have been given in the text and tables. Values of $p$ of "0.000" given by the statistics package have been recorded as $<0.0005$. Further details are described in the Results section where appropriate.

Concerning the FAIS data, only the onset and the offset of surface activity were estimated so far. To do this, for each animal and each day the times of the first (in the evening) and the last signal (in the morning) were taken from the data files. A mean value was calculated for each animal and thereafter for all animals investigated in the same experiment.

\section{Results}

The daily activity patterns of young adult hamsters obtained under highly standardized laboratory conditions are shown in Figure 1. To describe these rhythms more formally, the amount of motor activity per day and the percentage of total activity accounted for the dark period were estimated (Fig. 2). Comparing the species, activity level was lowest in $P$. campbelli and highest in $P$. roborovskii. Females were more active than males. However, none of these differences was significant (ANOVA). The same was true for the darkperiod activity. All animals were active almost exclusively during the dark time. Though, the onset of activity was significantly later in $P$. campbelli than in the two other species (Fig. 3, p < 0.005)). The activity offset was earliest in $P$. roborovskii ( $\mathrm{p}<0.0005)$. Animals of this species also had the shortest duration of dark-time activity ( $\mathrm{p}<0.005)$. No gender-specific differences were found.

Running wheels were used nearly exclusively during the dark time of the LD cycle - on average, $97 \%$ of 


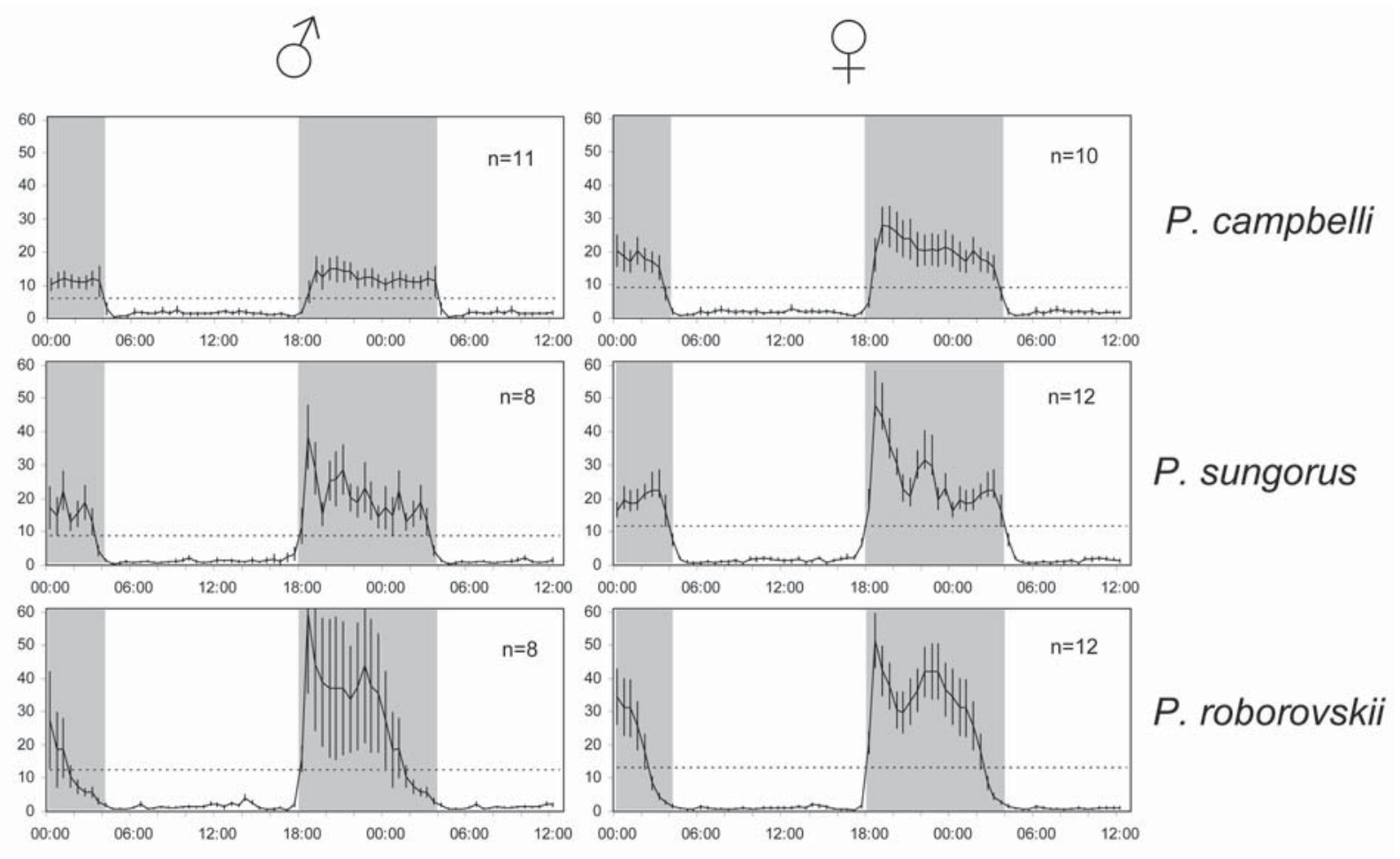

Figure 1. Daily pattern of motor activity of young adult hamsters (19-21 weeks old) of the genus Phodopus obtained by means of PIR detectors.

For every animal, a mean value chronogram was calculated (48 data points per $24 \mathrm{~h}$, each of which representing a mean value of 14 days). These chronograms were summarized according to sex and species. Mean values and standard errors are depicted. The corresponding numbers of animals are indicated in the upper right corner of each graph. For better visualization, 1.5 periods are shown, that means the last 24 data points $(=12 \mathrm{~h})$ are identical with the first 24 ones. Abscissa: Time of day in h. Ordinate: Motor activity in counts/30min (60 was taken as the upper limit in each case to make the curves comparable, even though in male P. roborovskii, three error bars were cut off this way). The daily means are shown as dashed lines in each panel. The dark period of the LD cycle is indicated by a grey background.
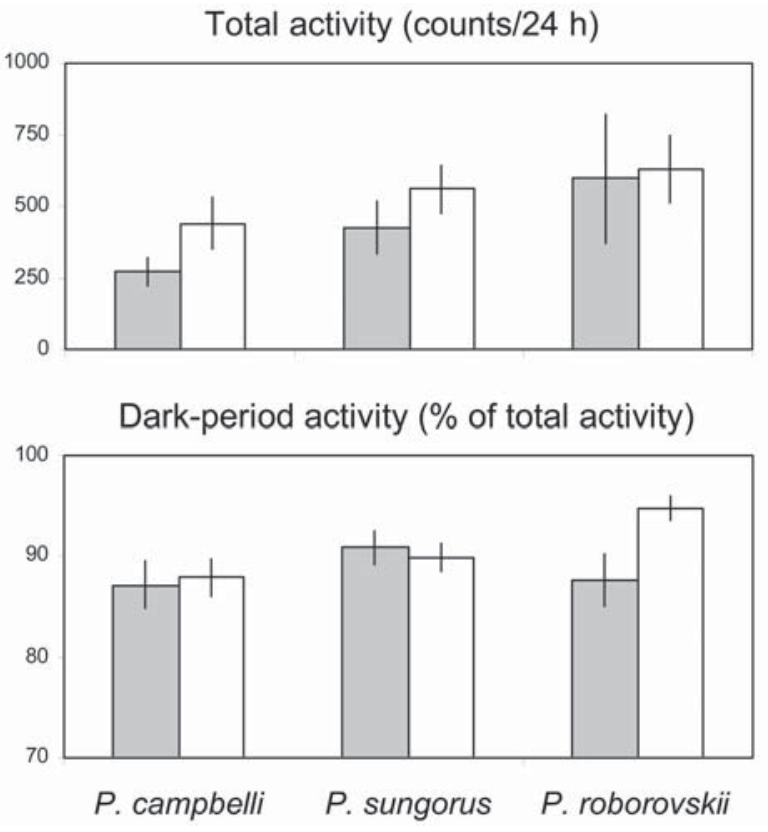

Figure 2. Characteristics of the daily activity patterns. The data from Figure 1 were analysed and mean values and standard errors are shown. Grey columns: male hamsters; white columns: female hamsters. the total wheel revolutions. ANOVA did not reveal species or gender specific differences. The daily amount of activity (wheel revolutions per $24 \mathrm{~h}$ ) was also not different between male and female hamster. Though, $P$. sungorus were significantly more active than the animals the other two species (Fig. 4). On average, they realized 9000 revolutions per $24 \mathrm{~h}$, what equals to about $3.5 \mathrm{~km}$.

Rhythm stability (Qp) was lowest in P. sungorus ( $\mathrm{p}<$ 0.005; Fig. 5). In all species it tended to be higher in females, however only in $P$. campbelli the difference was significant $(\mathrm{p}<0.05)$.

Another peculiarity of $P$. sungorus concerns the onset of the main activity period. Normally, motor activity increases around the light-dark transition. In some hamsters however, the onset was delayed considerably (Fig. 6). The activity offset remained synchronized with the dark-light transition. As a consequence, the activity period was compressed up to a certain critical point. Thereafter the activity rhythm did free run or disappeared.

Differences between species were also found in the weeks before animals died. $P$. campbelli $(n=6)$ showed a clear activity rhythm until the last day of life, though with a decreasing amplitude. The activity onset in the evening was about 00:45 h later than lights-off, a simi- 


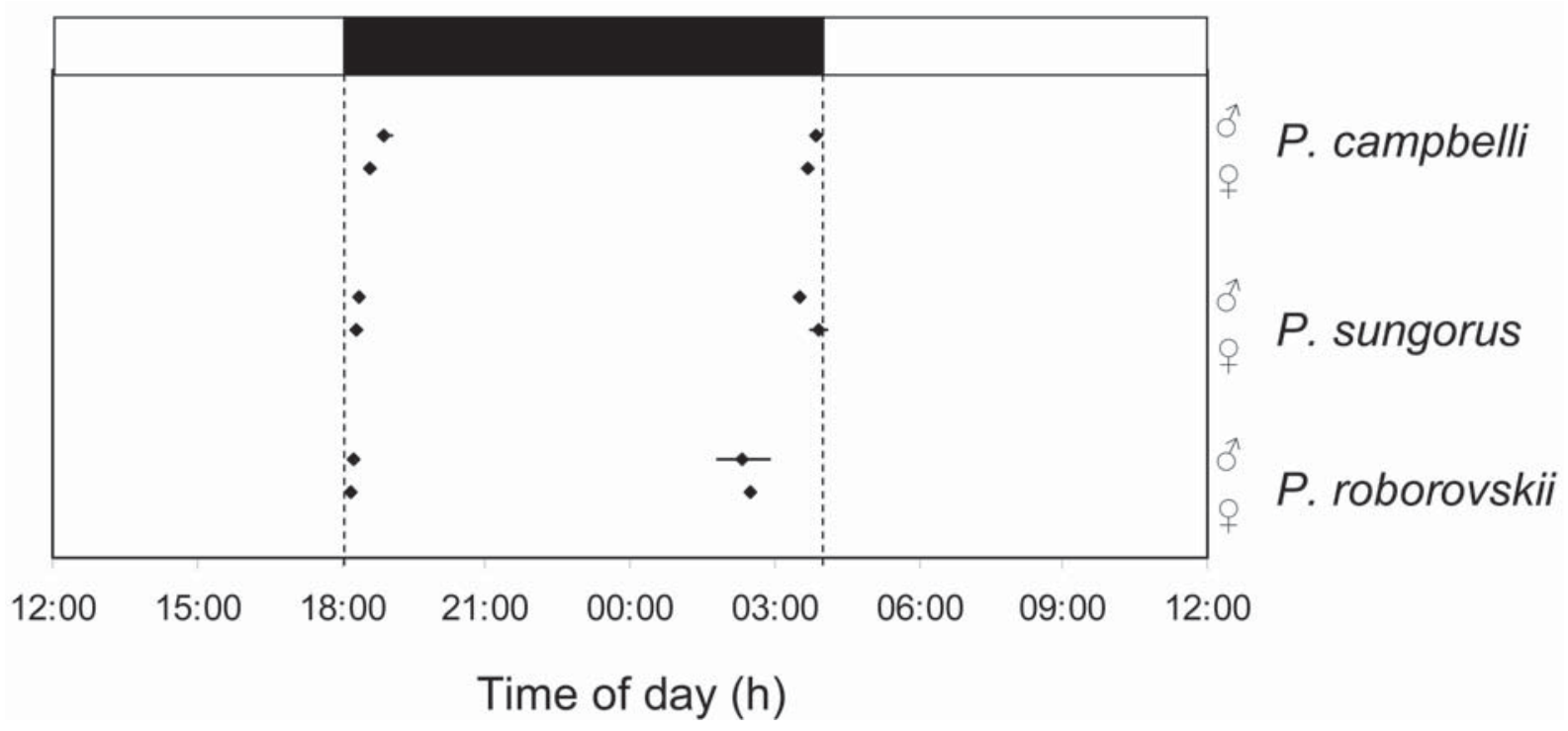

Figure 3. Activity onsets and offsets (data from Fig. 1). Mean values and standard errors are shown. The black and white bars on the top and the vertical lines indicate the light-dark regimen.

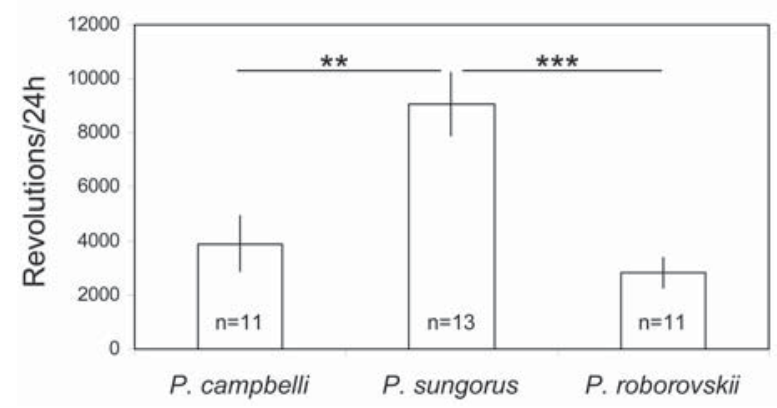

Figure 4. Running wheel activity of young adult hamsters (18-30 weeks old) kept under LD-conditions. Mean values over 10 days and standard errors are shown. As ANOVA did not reveal gender-specific differences, values of male and female animals were summarized. Significant species differences are indicated by asterisks $(* *-\mathrm{p}<0.005, * * * \mathrm{p}<$ 0.0005; two-tailed t-test).

lar value as has been observed in young adult animals. The hamsters died at different ages between 81 and 151 weeks (mean value: 115 wks.). In $P$. sungorus $(\mathrm{n}=11)$, the activity rhythm was less clear during the last weeks of life. In five of them, motor activity was evenly distributed over the day. In all animals, the evening activity onset was delayed as compared to younger hamsters, and this delay tended to increase until they died between 90 and 146 weeks of age (mean value: 123 weeks). Also in $P$. roborovskii $(\mathrm{n}=5)$, activity rhythms could be observed until their natural death occurring at a mean age of 133 weeks ( 83 - 175 weeks). The activity onset did coincide with the time of light-off as it was observed also in young adult animals. Only during the last 4 to 8 days of life, the activity rhythm

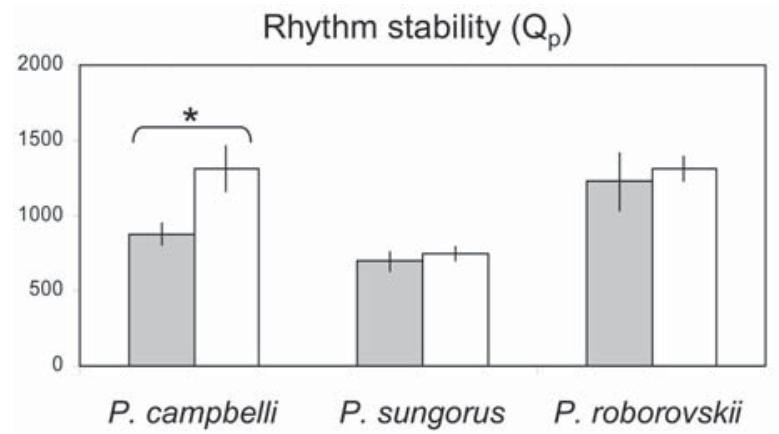

Figure 5. Stability of the daily activity rhythm.

The data from Figure 1 were analysed and mean values and standard errors are shown. Grey columns: male hamsters; white columns: female hamsters* $-\mathrm{p}>0.05$ (two-tailed t-test)

became less clear. In two animals, the activity rhythm ran free for 3-4 weeks until they died. The period length was shorter than $24 \mathrm{~h}$.

To describe the activity patterns during the last weeks of life more formally, the total amount of activity per day, per 14 hours of light and 10 hours of dark and the percentage of motor activity per 24 hours accounted for the dark-period were estimated. The activity level of old $P$. campbelli and $P$. roborovskii was much less than in the young adult controls. Though, the dark-light difference was still high, except the last two decades. The total activity per day decreased to a lesser extent in old $P$. sungorus. However, there was almost no darklight difference. The activity during the light period was elevated, and the activity during the dark period 


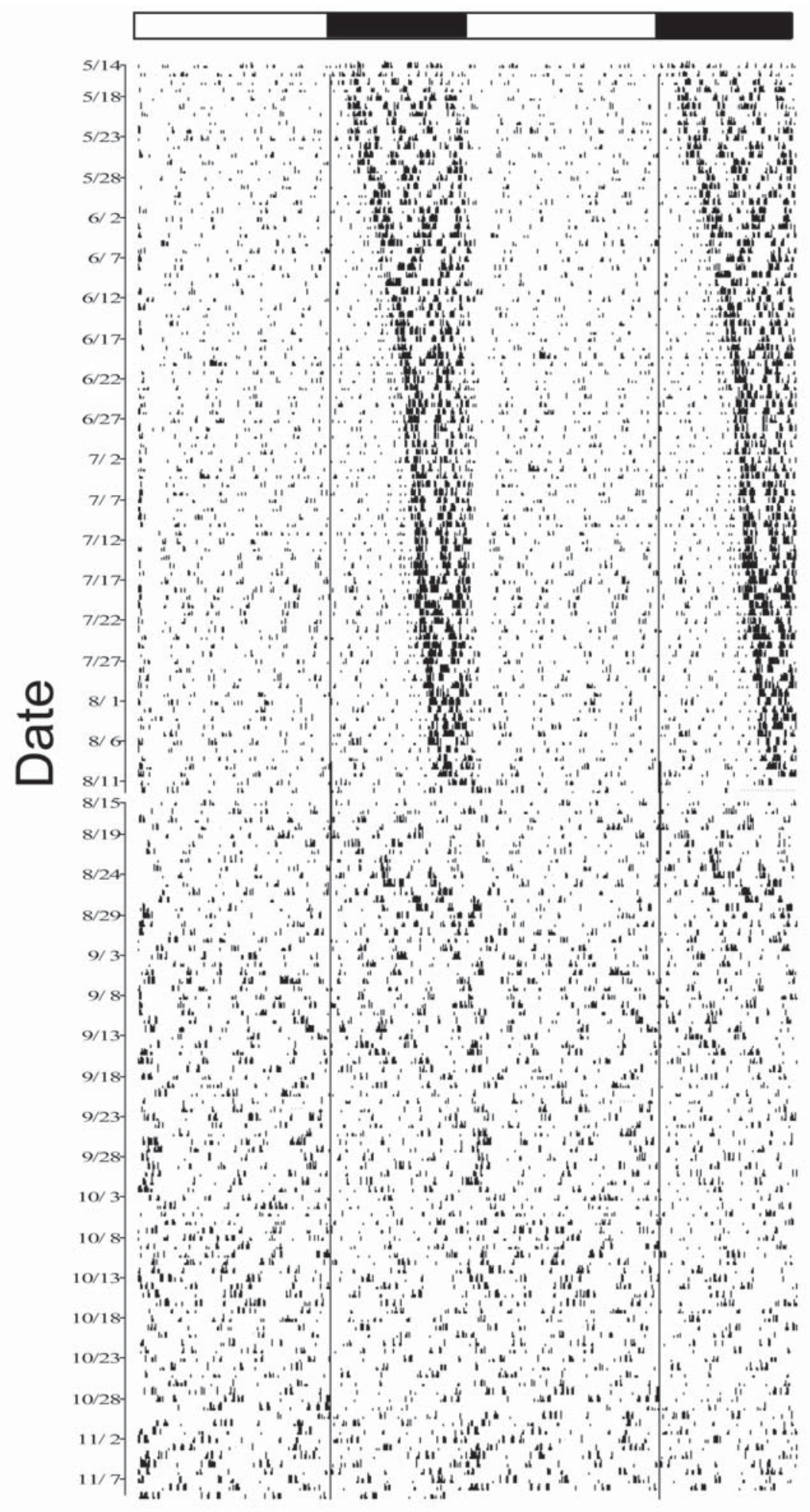

Figure 6. Daily activity pattern of a male hamster (P. sungorus) kept under L:D = 14:10. At the beginning of the experiment, the animal was 10 weeks old. Motor activity was recorded by the mean of PIR detectors. The data are double plotted. The ordinate shows the dates of experiment. The black and white bars on the top and the vertical lines indicate the light-dark regimen. 


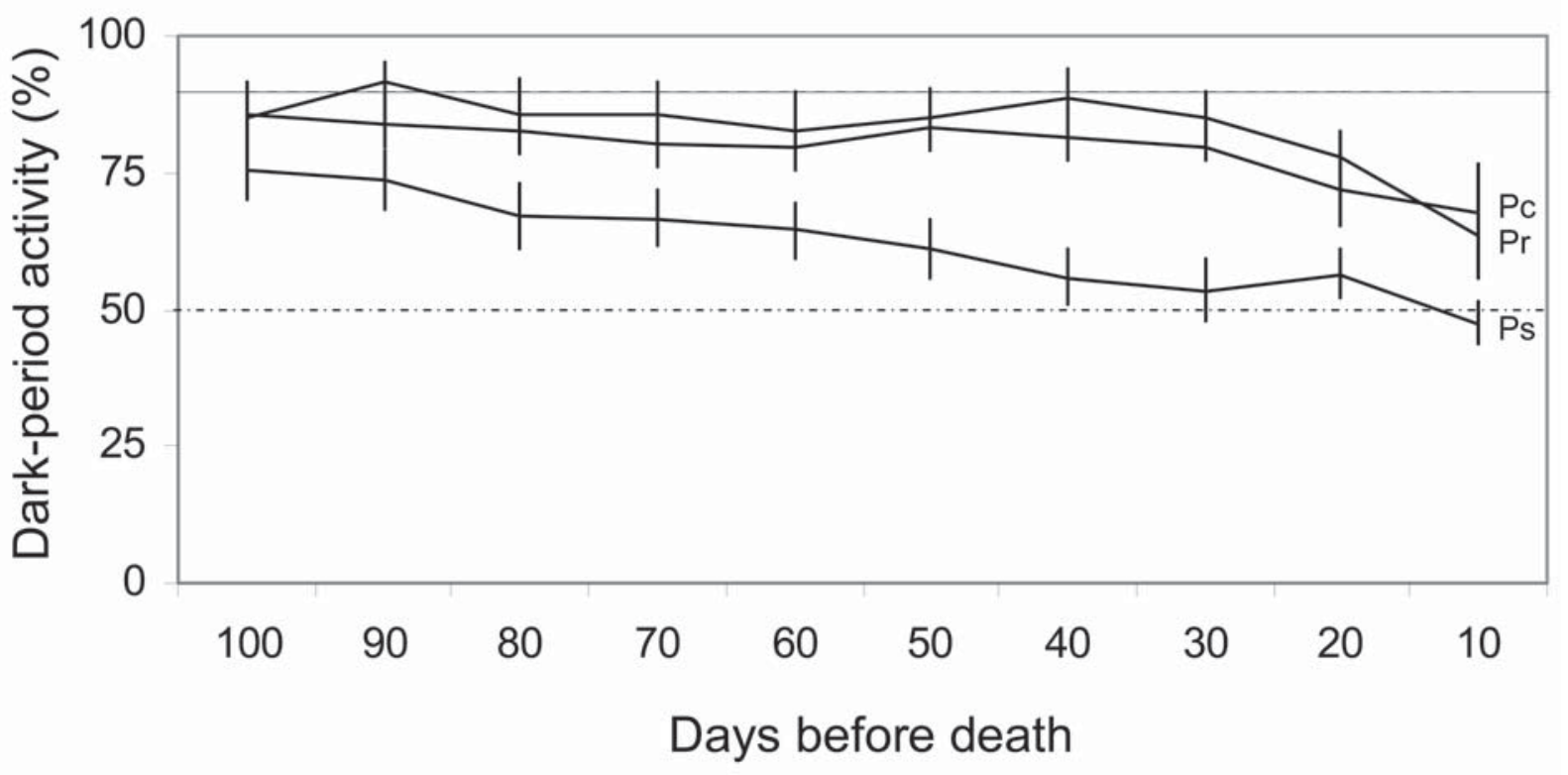

Figure 7. Percentage of motor activity per day accounted for the dark period during the last 100 days of life. Mean values and standard errors are shown. The thin vertical line indicates the mean value for the young adult hamsters (89\%; cf. Fig. 2). As ANOVA did not reveal inter-specific differences, the data of all three species were summarized. The numbers on the abscissa indicate 10-d periods before animals died (1 to $10 \mathrm{~d}$ before death — "10"; 11 to $20 \mathrm{~d}$ before death "20" etc.), Pc - P. campbelli, Ps - P. sungorus, $\mathrm{Pr}-P$. roborovskii.

was reduced. The differences between the hamster species become even more obvious considering the darkperiod activity as percentage of the 24-h activity (Fig. 7). ANOVA revealed highly significant effects of time $(\mathrm{p}<0.0005)$ and species $(\mathrm{p}<0.0005)$ but no interaction. The post-hoc test (Scheffé) revealed no difference between $P$. campbelli and $P$. roborovskii but, in both species the dark-period activity was significantly higher $(p<0.0005)$ than in $P$. sungorus. In the latter, the mean dark-period activity was significantly less than in young adult hamster at all intervals of the last 100 days of life and did not exceed $50 \%$ during the last 50 days (Table 1). In the two other species, the percentage was not different from young adult control animals and higher than $50 \%$, except the last 10 days of life.

The activity patterns obtained under L:D = 18:06 and under natural lighting conditions were similar to those described above but with a clear response to changes of the photoperiod. Figure 8 depicts the mean activity onsets and offsets obtained in laboratory studies though with different lighting conditions. As no gender differences were found (see above), the data of both sexes were summarized. The middle part of the figure shows the results obtained during July and August at the Biological station in Tchernogolovka. $P$. sungorus did start its activity around sunset and stopped it around sunrise. The results for the other two species were similar, though $P$. roborovskii did finish earlier and $P$. campbelli began later. The graph at the bottom shows the same data as Figure 3 though ignoring gender. The light-dark regimen with $14 \mathrm{~h}$ of light corre- sponds to the natural lighting conditions in Tchernogolovka at the end of August. A laboratory study under standardized conditions and an L:D $=18: 06 \mathrm{~h}$ was performed as this corresponds to the natural lightdark changes at the end of June. Activity onsets and offsets are shown at the top of Figure 8. They confirm the results obtained in the other studies, except the activity offset of $P$. roborovskii was not earlier with respect to the other species.

First results obtained in outdoor enclosures mainly confirm the laboratory studies. Surface activity was observed nearly exclusively during the dark hours of the day. On average, the onset of activity did coincide with the end of civil twilight (Fig. 9). This was than in the laboratory study (cf. Fig. 8). Most likely, this difference was due to the lower light intensity in the laboratory and the earlier "end of civil twilight" there. Accordingly, the offset of activity in the morning was found to be earlier as compared to the laboratory, though the variability was rather high. Almost no activity was observed after sunrise. However, further studies are necessary for a more detailed analysis also with respect to putative differences between the two types of outdoor enclosures and between species.

\section{Discussion}

The amount of motor activity measured by means of PIR detectors was statistically not different between the species, though there was a tendency towards higher activity in $P$. roborovskii. The latter fits well with our 
Table 1. Percentage of 24-h activity accounted for the dark period. Two-tailed t-test of the data depicted in Fig. 7. $\mathrm{P}$-values indicating a significant difference $(\mathrm{p}<0.05)$ are given in bold numerals.

\begin{tabular}{|l|c|c|c|c|c|c|}
\hline Test value & \multicolumn{3}{|c|}{$89 \%$ (mean value of young adult hamsters) } & \multicolumn{3}{c|}{$50 \%$ (even distribution between the dark and the } \\
light periods)
\end{tabular}

25.06.2007

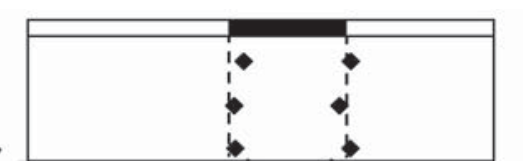

05.07.2007

15.07.2007

25.07.2007

04.08.2007

14.08.2007

24.08.2007

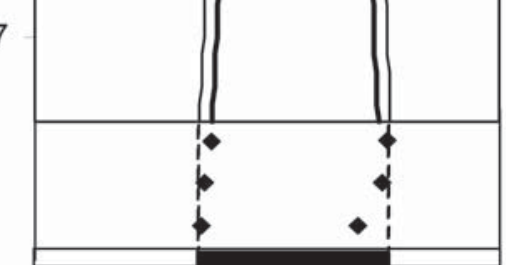

P. campbelli $(\mathrm{n}=6)$

$P$. sungorus $(n=6)$

$P$. roborovskii $(n=6)$<smiles>c1ccccc1</smiles>

$L: D=18: 06 h$

P. sungorus $(n=6)$

P. roborovskii $(\mathrm{n}=6)$

P. campbelli $(\mathrm{n}=12)$

P. sungorus $(n=6)$

P. roborovskii $(\mathrm{n}=6)$

Natural lighting

- sunset/sunrise

- start/end of civil twilight

. campbelli $(\mathrm{n}=21)$

$P$. sungorus $(\mathrm{n}=20)$

$P$. roborovskii $(n=20)$

\section{$L: D=14: 10 h$}

Figure 8. Activity onset and offset of dwarf hamsters depending on the lighting conditions. Animals were investigated under laboratory conditions but with natural (middle part) or artificial (top and bottom) light-dark changes. 


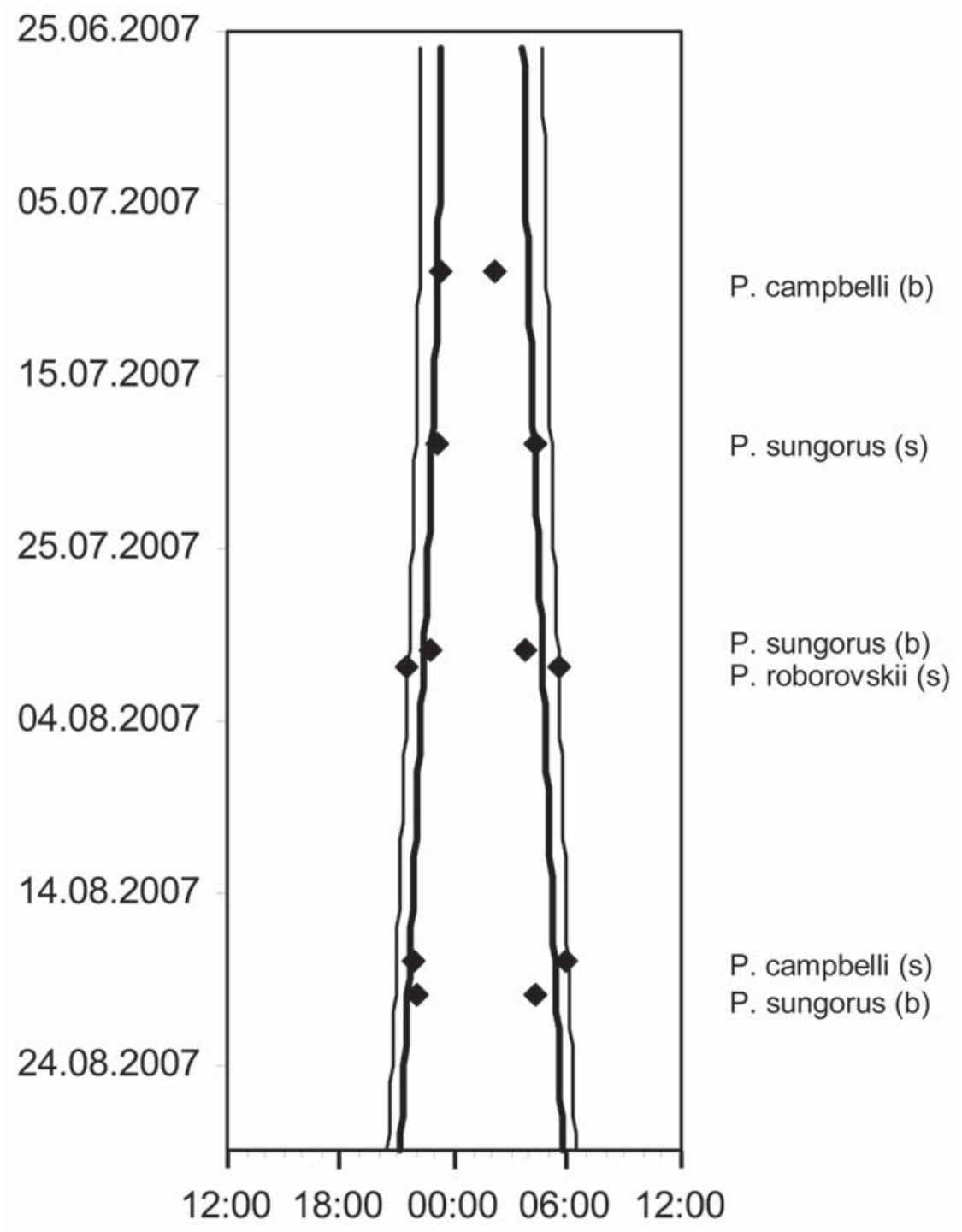

Figure 9. Activity onset and offset of dwarf hamsters kept in outdoor enclosures. Depicted are mean values from 4 to 6 animals at the day corresponding to the middle of the investigation period (2-3 weeks in each case). The letters in parentheses indicate the location ( $\mathrm{b}$ - big enclosure, $\mathrm{s}$ - small enclosure). Thin lines: sunset and sunrise; bold lines: onset and offset of civil twilight.

visual observation. In accordance with Hamann (Hamann, 1987), we found $P$. campbelli and $P$. sungorus to be slow and sluggish, whereas $P$. roborovskii were lively, nimble and agile animals moving with short, jerky, almost nervous movements.

Differences between species were found concerning wheel running activity. $P$. sungorus did run significantly more than the hamsters of the other two species. Similar results were found by Hamann (Hamann, 1987), who compared the running wheel activity of $P$. roborovskii and $P$. sungorus. The results also fit with the observation of Feoktistova and Mesherski (Feoktistova \& Meshcherskii, 2003) that, the exploratory activity in the open field is higher in $P$. sungorus than in $P$. roborovskii. According to others, wheel running activity can be taken as an estimate of the exploratory/ foraging behavior of the animals (Rusak, 1989; Wollnik et al., 1991). These results would imply that $P$. sungorus has a bigger home range and performs longer excursions. This can only be verified by studies in the natural environment or under conditions close to natural ones.

Hamsters of all three species were active almost exclusively during the dark time. Differences were found for the activity onset which was latest in P. campbelli. $P$. roborovskii had the shortest activity time due to a significantly earlier offset. This was true not only under artificial light-dark conditions but also under natural ones. First studies in outdoor enclosures confirm the nocturnal type of activity and the photoperiodic change 
of activity onsets and offsets. Though, species differences could not be verified so far.

Wynne-Edwards and colleagues (Wynne-Edwards et al., 1999) investigated the above-ground activity in wild populations of $P$. campbelli and $P$. sungorus during three successive years. Both were nocturnal. However, $P$. campbelli arose earlier and remained above ground longer than $P$. sungorus. Individual $P$. campbelli often emerged before dark and remained above ground after dawn. No P. sungorus emerged before dark but, few were active after dawn. Daily patterns of wheel running confirmed the differences between species seen in the wild (Wynne-Edwards et al., 1999). Also under controlled laboratory conditions, $P$. campbelli began running earlier, remained running longer, and had run "farther" by the end of the day. This was taken as evidence that differences between species in the wild were not simply responses to different environmental stimuli but have a genetic basis as a result of divergent evolution.

According to Wynne-Edwards and colleagues (Wynne-Edwards et al., 1999), the activity patterns reflect differences in the habitats used. $P$. campbelli is found in a semi-desert, where resource availability (nutrient and water) is more limited as compared to the short-grass steppe, where $P$. sungorus naturally occurs. Thus, it could be forced to travel farther from the burrow and to spend more time above ground as compared to $P$. sungorus. However, resource availability cannot be the only reason for differences in the activity pattern. Other factors must be taken into account as well. For example, animals must avoid social interactions including risk of predation and temporal niche segregation from other syntopic species (Cohen \& Kronfeld-Schor, 2006). Also, resource availability changes in the course of the year. This may change the home range and accordingly the amount of above ground activity. Another factor to be considered is the breeding season, when the males have to find mates. For example, within three weeks at the beginning of September, the home range of $P$. campbelli becomes several times smaller (Surov, unpublished observations). At that time, the breeding season is almost over. Also, Caragana seeds have ripened, a high energy food resource that is easy available for the animals.

The activity patterns described in the present paper are rather similar under different environmental conditions. In particular, the activity onsets and offsets differ in a species dependent manner. Although some of the results obtained in the outdoor enclosures are preliminary ones, this can be taken as evidence that the activity patterns and the species differences do reflect genetic differences. That not all results of the present paper are consistent with those obtained by Wynne-Edwards and colleagues may be caused by the different origin of the hamsters. There are two distinct forms of P.campbelli (Surov \& Feoktistova, 2006). One inhabits Western Mongolia (Valley of Great Lakes) up to Russia (Tuva region and Altai). Animals of this origin were used by
Wynne-Edwards, whereas we had hamsters from the east. This form lives from Hangay mountains and up to the East of Mongolia, Manchuria and Inner Mongolia. Both forms are not very different phenotypically but, the habitats are quite different. The western form prefers more open areas with sparse grass and shrubs, whereas the eastern form lives in very grassy places. Even more important seem to be the differences concerning population density. Usually, $P$. campbelli has a lower density but, this is true only for the western form. In the east, the density is very high. In 2004, we caught 14 animals (including 6 adults) by 70 living traps ( $5 \mathrm{~m}$ apart from each other) for 1 night near Ugyi-nur (Mongolia). The same or even higher density was observed in colonies of $P$. roborovskii in certain years. In July 2004, we marked 18 animals for 3 trap-nights on a onehectare plot in Mongolia. Eleven of them were sexually matured. In such a high density there is no reason to search for mates far away.

The most striking inter-specific difference found in the present paper probably concerns the rhythm stability that was lowest in $P$. sungorus. This was true not only for young adult animals but also for the last weeks of life. $P$. campbelli and $P$. roborovskii both revealed a stable activity pattern, though with a lower amplitude, except for the very last days. This fits well with our earlier observation that the circadian clock is very robust and still working in old age (Weinert et al., 2001; 2002). In P. sungorus on contrary, the locomotor activity was almost evenly distributed over the 24-h day. The reason for a lacking overt rhythm might be a weak circadian clock or a motor disability, not allowing to transform the rhythmic signal from the clock (Weinert, 2005). In the case of $P$. sungorus, one must consider mainly deficits in the circadian system, as also other peculiarities were found. In some animals, the activity onset was delayed leading to a compression of the activity time. As a consequence, the rhythm started to free run despite the presence of a light-dark cycle or disappeared. As a reason for, we suggest a diminished ability to synchronize (Weinert \& Schöttner, 2007).

Also others have found some unusual characteristics in the circadian system of this species that appear incompatible with proper function in photoperiodic time measurement. For instance, in certain laboratory colonies of $P$. sungorus a substantial fraction of hamsters does not respond to a short photoperiod. These so called non-responders fail to decompress their activity phase in a short photoperiod, and do not undergo gonadal regression (Puchalski \& Lynch, 1988). In the studies of Ruby and colleagues part of the hamsters became arrhythmic or free-ran after a phase delay of the light-dark cycle (Ruby et al., 1998). According to Steinlechner and co-authors (Steinlechner et al., 2002), a combination of two light pulses in two subsequent nights did cause arhythmicity in a large fraction of their animals. All these phenomena, including those described in the present paper, may derive at least partly from a similar origin. 


\section{Conclusions}

The results of the present paper show that, the methods used are suitable to characterize the endogenous component of the circadian activity rhythm. To investigate the activity behavior more detailed, particularly to differentiate between various kinds of behavior, one needs a combination of different methods. The passive infrared motion sensors detect any kind of movement and thus are suitable for investigations under laboratory and semi-natural conditions. They provide a good quantitative estimate. To differentiate between various kinds of behavior, additional video tracking can be helpful. Also the ring-shaped sensors placed on burrow entrances have been successfully used. They may provide more information than analyzed in this first preliminary study as they detect any entrance into and exit from a burrow individually.

Further experiments are necessary to better understand the specific role of genetic and environmental factors for the expression of a certain rhythmic phenotype. These studies should involve not only hamsters of different species but also animals of the same species but with a different geographic origin. Investigations should be performed under laboratory conditions, where the environmental factors can be controlled exactly. In addition, studies under semi-natural conditions and finally field studies are necessary to investigate if the obtained differences remain in the natural habitat and if they are of adaptive significance.

ACKNOWLEDGMENTS. The study was supported by grants of the German Academic Exchange Service (DAAD), the German Research Foundation (WE 1697/11-1) and the Russian Foundation for Basic Research (grant \# 09-04-00701-a). Special thanks to Andreas Müller from the Department of Physics of the University of Halle, Germany for development and preparation of FAIS.

\section{References}

Bae H.H., Larkin J.E. \& Zucker I. 2003. Juvenile Siberian hamsters display torpor and modified locomotor activity and body temperature rhythms in response to reduced food availability // Physiological \& Biochemical Zoology. Vol.76. P.858-867.

Barakat M.T., O'Hara B.F., Cao V.H., Heller H.C. \& Ruby N.F. 2005. Light induces c-fos and per1 expression in the suprachiasmatic nucleus of arrhythmic hamsters // American Journal of Physiology Regul. Integr. Comp Physiol. Vol.289. P.R1381-R1386.

Cohen R. \& Kronfeld-Schor N. 2006. Individual variability and photic entrainment of circadian rhythms in golden spiny mice // Physiology \& Behavior. Vol.87. P.563574.

Feoktistova N.Yu. \& Meshcherskii I.G. 2003. [Function of chemical signals in interspecific relationships of sympatric and allopatric hamster species of the genus Phodo- pus (Rodentia: Cricetinae)] // Doklady Akademii Nauk. Vol.389. P.846-849 [in Russian].

Flint WE. 1966. Die Zwerghamster der paläarktischen Fauna. Wittenberg: A. Ziemsen Verlag. 97 S.

Hamann U. 1987. Zu Aktivität und Verhalten von drei Taxa der Zwerghamster der Gattung Phodopus Miller, 1910 // Zeitschrift für Säugetierkunde. Vol.52. P.65-76.

Hoffmann K. \& Illnerova H. 1986. Photoperiodic effects in the Djungarian hamster. Rate of testicular regression and extension of pineal melatonin pattern depend on the way of change from long to short photoperiods// Neuroendocrinology. Vol.43. P.317-321.

Hume J. M. \& Wynne-Edwards K.E. 2006. Paternal responsiveness in biparental dwarf hamsters (Phodopus campbelli) does not require estradiol // Hormones and Behavior. Vol.49. P.538-544.

Jefimow M. 2007. Effects of summer- and winter-like acclimation on the thermoregulatory behavior of fed and fasted desert hamsters, Phodopus roborovski i// Journal of Thermal Biology Vol.32. P.212-219.

Larkin J.E., Freeman D.A. \& Zucker I. 2001. Low ambient temperature accelerates short-day responses in Siberian hamsters by altering responsiveness to melatonin // Journal of Biological Rhythms. Vol.16. P.76-86.

Mrosovsky N., Salmon P.A. \&Vrang N. 1998. Revolutionary science: an improved running wheel for hamsters // Chronobiology International. Vol.15. P.147-158.

Puchalski W. \& Lynch G.R. 1988. Characterization of circadian function in Djungarian hamsters insensitive to short day photoperiod // Journal of Comparative Physiology [A]. Vol.162. P.309-316.

Puchalski W., Saarela S. \& Lynch G.R. 1996. Reentrainment of motor activity and spontaneous neuronal activity in the suprachiasmatic nucleus of Djungarian hamsters // Journal of Biological Rhythms. Vol.11. P.302-310.

Ruby N.F., Barakat M.T. \& Heller H.C. 2004. Phenotypic differences in reentrainment behavior and sensitivity to nighttime light pulses in siberian hamsters // Journal of Biological Rhythms. Vol.19. P.530-541.

Ruby N.F., Joshi N. \& Heller H.C. 1998. Phase shift magnitude and direction determine whether Siberian hamsters reentrain to the photocycle // Journal of Biological Rhythms. Vol.13. P.506-517.

Ruf T., Stieglitz A., Steinlechner S., Blank J.L. \& Heldmaier G. 1993. Cold exposure and food restriction facilitate physiological responses to short photoperiod in Djungarian hamsters (Phodopus sungorus) // Journal of Experimental Zoology Vol.267. P.104-112.

Rusak B. 1989. The mammalian circadian system: models and physiology // Journal of Biological Rhythms. Vol.4. P.121-134.

Steinlechner S., Stieglitz A. \& Ruf T. 2002. Djungarian hamsters: a species with a labile circadian pacemaker? Arrhythmicity under a light-dark cycle induced by short light pulses // Journal of Biological Rhythms. Vol.17. P.248-258.

Surov A.V. \& Feoktistova N.Yu. 2006. [Biology of dwarf hamsters and using them in laboratory studies] // Biomedicina. Vol.2. P.52-70 [in Russian].

Timonin M.E. \& Wynne-Edwards K.E. 2006. Neither reduced photoperiod, nor female-related social cues, nor 
increased maternal thermal stress result in a paternally responsive Phodopus sungorus male // Physiology \& Behavior. Vol.88. P.309-316.

Weinert D. 2005. The temporal order of mammals. Evidence for multiple central and peripheral control mechanisms and for endogenous and exogenous components: some implications for research on aging // Biological Rhythm Research Vol.36. P.293-308.

Weinert D. \& Schöttner K. 2007. An inbread lineage of Djungarian hamsters with a strongly attenuated ability to synchronize // Chronobiology International. Vol.24. P.115.

Weinert H., Weinert D., Schurov I., Maywood E.S. \& Hastings M.H. 2001. Impaired expression of the mPer2 circadian clock gene in the suprachiasmatic nuclei of aging mice // Chronobiology International. Vol.18. P.559-565.
Weinert H., Weinert D. \& Waterhouse J. 2002. The circadian activity and body temperature rhythms of mice during their last days of life // Biological Rhythm Research Vol.33. P.199-212.

Wollnik F., Breit A. \& Reinke D. 1991. Seasonal change in the temporal organization of wheel-running activity of the European hamster, Cricetus cricetus // Naturwissenschaften. Vol.78. P.419-422.

Wynne-Edwards K.E. 1998. Evolution of parental care in Phodopus: Conflict between adaptations for survival and adaptations for rapid reproduction // American Zoologist. Vol.38. P.238-250.

Wynne-Edwards K.E., Surov A.V. \& Telitzina A.Y. 1999. Differences in endogenous activity within the genus Phodopus // Journal of Mammalogy. Vol.80. P.855-865. 